\title{
Avaliação da atividade antimicrobiana de Maytenus rigida Mart. (Celastraceae)
}

\author{
SANTOS, V.L. ${ }^{1 *}$; SOUZA, M.F.V. ${ }^{2}$; BATISTA, L.M. ${ }^{2}$; SILVA, B.A. ${ }^{2}$; LIMA, M.S. ${ }^{2}$; SOUZA, A.M.F."; BARBOSA, \\ F.C. ${ }^{1}$; CATÃO, R.M.R. ${ }^{1}$ \\ 'Universidade Estadual da Paraíba/Departamento de Farmácia, Rua Baraúnas, 351, Bairro Universitário, CEP: \\ 58429-500, Campina Grande-Brasil ${ }^{2}$ Universidade Federal da Paraíba/Laboratório de Tecnologia Farmacêutica, \\ Cidade Universitária, CEP: 58059-900, João Pessoa-Brasil *vanda.farmaciauepb@yahoo.com.br
}

\begin{abstract}
RESUMO: A realização de estudos farmacológicos é fundamental para comprovar a eficácia do uso de plantas medicinais pela população para o tratamento de doenças e descobrir novos fitoterápicos. Esse estudo teve como objetivo avaliar o potencial antimicrobiano do extrato etanólico e fase acetato de etila do bom nome (Maytenus rigida Mart.) sobre Staphylococcus aureus ATCC 25923, 3 amostras de Staphylococcus aureus multirresistentes isoladas de pacientes com infecções nosocomiais, Escherichia coli ATCC 25922, Pseudomonas aeruginosa ATCC 27853 e Salmonella sp. (228-R-Tet, 118-R-Sut e 01-S) isoladas de ambiente aquático, utilizando o método de difusão em agar. Os testes revelaram que o extrato e fase de $M$. rigida apresentaram atividade antimicrobiana in vitro frente a todas as cepas de $S$. aureus testadas, apresentando concentração inibitória mínima (MIC) de $400 \mathrm{mg} \mathrm{mL}^{-1}$. Entretanto, estes produtos não apresentaram atividade frente às linhagens de bactérias Gram-negativas testadas, Escherichia coli, Pseudomonas aeruginosa e Salmonellasp.
\end{abstract}

Palavras-chave: Maytenus rigida, bom nome, Celastraceae, atividade antibacteriana, plantas medicinais

\begin{abstract}
Evaluation of the antimicrobial activity of Maytenus rigida Mart. (Celastraceae). Ppharmacological studies are essential to prove the effectiveness of using medicinal plants to treat diseases and discover new phytotherapics. This study aimed to evaluate the antimicrobial potential of ethanol and ethyl acetate extracts of "bom-nome" (Maytenus rigida Mart.) against Staphylococcus aureus ATCC 25923, three samples of multiresistant Staphylococcus aureus isolated from patients with nosocomial infections, Escherichia coli ATCC 25922, Pseudomonas aeruginosa ATCC 27853 and Salmonella sp. (228-R-Tet, 118-R-Sut and 01-S) isolated from water environment, using the agar diffusion test. Both extracts showed in vitro antimicrobial activity against all $S$. aureus strains, presenting $400 \mathrm{mg} \mathrm{mL}^{-1}$ minimum inhibitory concentration (MIC). However, these products did not show activity against strains of the Gram-negative bacteria Escherichia coli, Pseudomonas aeruginosa and Salmonella sp.
\end{abstract}

Key words: Maytenus rigida, "bom-nome', Celastraceae, antibacterial activity, medicinal plants

\section{INTRODUÇÃO}

De acordo com Organização Mundial de Saúde (OMS), 65 a 80\% da população de países em desenvolvimento fazem uso de plantas como recurso terapêutico alternativo. Porém, poucas destas plantas têm sido cientificamente estudas para determinar a qualidade, segurança e eficácia dos compostos (Calixto, 2005).

A avaliação dos efeitos farmacológicos de extratos vegetais é utilizada como estratégia para pesquisa de novos medicamentos de origem vegetal. O Brasil é o país com maior potencial para pesquisa com plantas medicinais por ter a mais rica biodiversidade do planeta, distribuído em seis biomas distintos (Noldin et al., 2006).

A família Celastraceae possui 88 gêneros e 1300 espécies distribuídas em climas tropicais e subtropicais (Spivey et al., 2002). O gênero Maytenus com cerca de 80 espécies distribuídas no Brasil, é

Recebido para publicação em 09/07/2009

Aceito para publicação em 05/05/2010

Rev. Bras. PI. Med., Botucatu, v.13, n.1, p.68-72, 2011. 
quimicamente caracterizado pela presença de triterpenos, alcalóides, taninos e flavonóides (González et al., 1982; Jorge et al., 2004).

Maytenus rigida Mart. popularmente conhecida como "bom nome", "chapéu de couro" ou "pau-decolher" é uma árvore de pequeno porte, que ocupa áreas muito secas da caatinga e agreste de Sergipe, Pernambuco e Paraíba (Andrade-Lima, 1989). De acordo com a medicina tradicional, o chá da entrecasca do caule é utilizado para problemas renais, como antiinflamatório, analgésico, cicatrizante, hipotensor, hepatoprotetor e para problemas gástricos (Carriconde, 2004), úlcera externa, infecção e câncer (Agra et al., 2007), impotência sexual e reumatismo (Almeida et al., 2005).

Estudos fitoquímicos de $M$. rigida mostram a presença de alcalóides (Delle et al., 1984), quinonas (Almeida et al., 2005) triterpenos da série lupano (Oliveira et al., 1999; Almeida et al., 2005), n-alcanos (Oliveira \& Salatino, 2000), esteróides, taninos e flavonóides (Estevam, 2006).

Ensaios farmacológicos com extratos desta espécie comprovaram atividade antinociceptiva (Dias et al., 2007), estimulante do Sistema Nervoso Central (Omena, 2007), antioxidante (Estevam, 2006), antidiarréica, antinflamatória, antiulcerogênica e antiespasmódica (Santos et al., 2007; Santos, 2008). No intuito de contribuir para o estudo farmacológico desta espécie, este trabalho tem como objetivo avaliar a atividade antimicrobiana in vitro do extrato etanólico e fase acetato de etila de Maytenus rigida, frente a cepas padrão ATCC e bactérias de origem ambiental e de infecção nosocomial.

\section{MATERIAL E MÉTODO}

A amostra de bom nome (Maytenus rigida Mart.) estudada constituiu-se da entrecasca do caule, coletada no Município de Aroeira/PB. A coleta foi realizada em janeiro de 2004. A planta foi identificada pela Profa Maria de Fátima Agra (UFPB) e um exemplar desta espécie está depositado no Herbário Lauro Pires Xavier da UFPB sob registro Agra et al. 3316 (JPB). O material vegetal $(3500 \mathrm{~g}$ ) foi seco em estufa de ar circulante, pulverizado e extraído por maceração com etanol $95 \%$. A solução obtida foi filtrada e concentrada em rotaevaporador para obtenção de extrato etanólico bruto, com rendimento de $14 \%$. O extrato etanólico bruto foi então tratado com acetato de etila e em seguida concentrado, resultando na fase acetato de etila (rendimento de $49,7 \%$ ).

O extrato e a fase acetato de etila, diluídos em água destilada esterilizada, foram testados nas concentrações entre 5000 - $200 \mathrm{mg} \mathrm{mL}^{-1}$. Os microorganismos utilizados para avaliação da atividade antimicrobiana e determinação da CIM foram Staphylococcus aureus ATCC 25923, Escherichia coli
ATCC 25922, Pseudomonas aeruginosa ATCC 27853 além de 3 amostras de Staphylococcus aureus (multirresistentes) isoladas de pacientes com diferentes infecções nosocomiais, em Campina Grande-PB, gentilmente cedidas pela Profa Patrícia Maria de Freitas da UEPB, e de 3 cepas de Salmonella sp. (228-R-Tet, 118-R-Sut e 01-S), isoladas de ambiente aquático e gentilmente cedidas pela Profa Maricelma Ribeiro Morais da UEPB.

Durante a realização do ensaio, as cepas foram mantidas em agar Mueller-Hinton (Difco) e repicadas para caldo Brain Heart Infusion-BHI (Difco) e incubadas a $37^{\circ} \mathrm{C} / 24$ horas. Após este período, procedeu-se o semeio pela técnica de estrias, em placas de Agar Sangue que foram incubadas a $37^{\circ} \mathrm{C} /$ 24 horas. Todas as cepas foram identificadas por meio de coloração de Gram e provas bioquímicas complementares.

Para determinação da atividade antimicrobiana e da Concentração Inibitória Mínima (CIM) do extrato e da fase do bom nome, tomou-se como referencial, o método de difusão em agar (Bauer et al.,1966), com adaptações, utilizando o processo cavidade-placa (técnica do poço) e seguindo as recomendações do National Committee for Clinical Laboratory Standart NCCLS (2003).

Inóculo - Os micro-organismos foram inoculados em caldo $\mathrm{BHI}$ e incubados a $37^{\circ} \mathrm{C} / 24 \mathrm{~h}$. Após este período realizou-se o subcultivo, transferindo-se $50 \mu \mathrm{L}$ do inóculo inicial para $50 \mathrm{~mL}$ de caldo Mueller-Hinton o qual foi incubado a $37^{\circ} \mathrm{C} / 1$ $\mathrm{h}$ de modo a produzir leve turvação, de densidade equivalente ao tubo 0,5 da escala de McFarland.

Semeio - O inóculo bacteriano foi semeado, na superfície das placas de Petri $(90 \times 15 \mathrm{~mm})$ contendo $20 \mathrm{~mL}$ de Agar Mueller-Hinton, com auxílio de swabs estéreis. Em seguida foram realizadas perfurações de $6 \mathrm{~mm}$ de diâmetro, com auxílio de perfuradores estéreis e descartáveis. Em cada cavidade, previamente identificada, foram depositados $50 \mu \mathrm{L}$ dos produtos em teste. As placas foram incubadas a $37^{\circ} \mathrm{C} / 24 \mathrm{~h}$.

A avaliação da atividade antimicrobiana in vitro determinada pelo método de difusão em meio sólido, foi realizada observando-se a formação de halos de inibição de crescimento ao redor das cavidades padronizadas. Foi considerado como produto ativo, neste estudo, aquele que apresentou halo de inibição de crescimento, com diâmetro igual ou superior a 8 mm (Wong-Leung, 1988; Naqui et al., 1991; Catão et al., 2005). Os ensaios foram realizados em duplicata e o resultado final foi determinado pela média aritmética dos diâmetros dos halos de inibição.

\section{RESULTADO E DISCUSSÃO}

Nas últimas décadas, muitos antibacterianos apresentam pouca eficácia no combate às doenças infecciosas, devido principalmente à alta incidência 
de infecções causadas por bactérias multirresistentes (Von Eiff et al., 2002), tornado-se um desafio para os profissionais da saúde, combater tais infecções. Dados da literatura sobre a atividade antibacteriana de extratos vegetais, avaliada frente a microorganismos sensíveis e resistentes a antibióticos, mostram o grande potencial das plantas para tratamento terapêutico, apesar de muitos destes extratos não terem sido completamente investigados cientificamente (Nascimento et al., 2000).

$\mathrm{Na}$ Tabela 1 estão apresentados os resultados da avaliação da atividade antimicrobiana, pelo método de difusão em agar (processo cavidadeplaca), do extrato etanólico bruto de $M$. rigida (bom nome) e a fase acetato de etila, sobre cepas padrão: S. aureus ATCC 25923, E. coli ATCC 25922, P. aeruginosa ATCC 27853; cepas de Salmonella sp. de origem ambiental e cepas de $S$.aureus de origem humana obtidas de infecções nosocomiais.

Segundo Silveira et al. (2009), o método de poços se baseia na difusão radial das substâncias, e a possível presença de partículas em suspensão na amostra a ser testada não interfere na difusão da substância antimicrobiana no agar, o que torna este método adequado para testar a difusão de substâncias em extratos etanólicos de plantas.

De acordo com os resultados obtidos verificou-se que tanto o extrato bruto quanto a fase apresentaram atividade sobre S. aureus ATCC 25923 apresentando halos de inibição de crescimento que variaram de 8 a $13 \mathrm{~mm}$ de diâmetro para o extrato e de 9 a $14 \mathrm{~mm}$ de diâmetro para a fase. Entretanto, estes produtos não foram eficazes para as demais cepas testadas, a E. coliATCC 25922, P. aeruginosa ATCC 27853 e Salmonella sp. (228-R-Tet, 118-R-Sut e 01-S), nas concentrações utilizadas.

Outras espécies de Maytenus apresentam atividade frente a bactérias Gram positivas e Gram negativas, a exemplo de $M$. macrocarpa (Kloucek et al., 2006), enquanto outras como a $M$. krukovii não apresentam atividade antimicrobiana significativa (Bruni et al., 2006). Esta variação em relação a presença de atividade antimicrobiana, pode estar relacionada não só a características da planta, uma vez que diferentes espécies apresentam diferentes princípios ativos, como também com as características das cepas testadas e da metodologia analítica empregada.

O fato desta espécie vegetal, não apresentar atividade antimicrobiana para bactérias Gram negativas, não inviabiliza os estudos sobre o potencial efeito antibacteriano, uma vez que outros gêneros e/ ou espécies vegetais, comprovadamente, apresentaram atividade antimicrobiana mais acentuada para micro-organismos Gram positivos. Dentre estes, pode-se citar o gênero Hypericum (Pistelli et al., 2002; Rabanal et al., 2002; França et al., 2009;) e a espécie Menta x villosa Hudson (Arruda et al., 2006).

A determinação da atividade antimicrobiana possibilitou a avaliação e a determinação da CIM com base na mensuração dos diâmetros dos halos de inibição de crescimento. Esta avaliação deve ser estudada caso a caso, principalmente quando se trata de estudos preliminares com extratos de plantas. Determinou-se como CIM $400 \mathrm{mg} \mathrm{mL}^{-1}$, para ambos

TABELA 1. Atividade antimicrobiana do extrato etanólico e fase acetato de etila de bom nome sobre as linhagens bacterianas de Staphylococus aureus ATCC, Escherichia coli ATCC, Pseudomonas aeruginosa ATCC, Salmonella sp. de origem ambiental e Staphylococcus aureus isolados de pacientes com infecção nosocomial.

\begin{tabular}{|c|c|c|c|c|c|c|c|c|c|c|c|c|c|c|}
\hline \multirow{3}{*}{\multicolumn{2}{|c|}{ MICRO-ORGANISMOS TESTADOS }} & \multicolumn{12}{|c|}{$\begin{array}{l}\text { PRODUTOS/CONCENTRAÇÃO }\left[\mathrm{mg} \mathrm{mL}^{-1}\right] / \text { diâmetro }(\mathrm{mm}) \text { halo de } \\
\text { inibição de crescimento }\end{array}$} & \multirow{3}{*}{ CCB } \\
\hline & & \multicolumn{6}{|c|}{ EXTRATO } & \multicolumn{6}{|c|}{ FASE } & \\
\hline & & 5000 & 2500 & 1250 & 625 & 400 & 200 & 5000 & 2500 & 1250 & 625 & 400 & 200 & \\
\hline \multirow{3}{*}{$\begin{array}{l}\text { Cepas } \\
\text { Padrão }\end{array}$} & S. aureus ATCC 25923 & 13 & 11 & 10 & 8 & 8 & 0 & 14 & 12 & 11 & 9 & 8 & 0 & + \\
\hline & E. coli A TCC 25922 & 0 & 0 & 0 & 0 & 0 & 0 & 0 & 0 & 0 & 0 & 0 & 0 & + \\
\hline & $P$. aeruginosa ATCC 27853 & 0 & 0 & 0 & 0 & 0 & 0 & 0 & 0 & 0 & 0 & 0 & 0 & + \\
\hline \multirow{3}{*}{$\begin{array}{l}\text { Cepas } \\
\text { Ambientais }\end{array}$} & Salmonella sp. (228-R-Tet) & 0 & 0 & 0 & 0 & 0 & 0 & 0 & 0 & 0 & 0 & 0 & 0 & + \\
\hline & Salmonella sp. (1 18-R-Sut) & 0 & 0 & 0 & 0 & 0 & 0 & 0 & 0 & 0 & 0 & 0 & 0 & + \\
\hline & Salmonella sp. (01-S) & 0 & 0 & 0 & 0 & 0 & 0 & 0 & 0 & 0 & 0 & 0 & 0 & + \\
\hline \multirow{3}{*}{$\begin{array}{l}\text { Cepas } \\
\text { Nosocomiais }\end{array}$} & S. aureus $1 \mathrm{P}$ & 13 & 12 & 10 & 08 & 08 & 0 & 12 & 11 & 09 & 08 & 08 & 0 & + \\
\hline & S. aureus $2 \mathrm{P}$ & 14 & 12 & 10 & 09 & 09 & 0 & 13 & 12 & 10 & 09 & 08 & 0 & + \\
\hline & S. aureus $3 \mathrm{P}$ & 13 & 12 & 11 & 09 & 09 & 0 & 13 & 12 & 10 & 08 & 08 & 0 & + \\
\hline
\end{tabular}

Legenda: 0 = Ausência de halo de inibição de crescimento. CCB $=$ Controle de crescimento bacteriano.+ = Viabilidade da cepa testada. 
os produtos, visto que foi a menor concentração que conseguiu apresentar halo de inibição de crescimento dos micro-organismos.

A atividade antimicrobiana in vitro é avaliada pela mensuração da CIM que pode ser feita pela medição de halos ou pela determinação dos níveis de resistência, entretanto estes procedimentos não determinam o tempo de ação sobre os microorganismos (May et al., 2000) e faz com que outros parâmetros farmacodinâmicos possam ser usados para determinar a eficácia antibacteriana, como por exemplo a cinética bacteriana (Mackenzie et al., 2002).

Os recentes avanços na identificação e compreensão dos novos mecanismos de ação dos antimicrobianos mostram que diversos fatores podem ser responsáveis pela potência de determinada substância, contribuindo de maneira diferenciada para a atividade antimicrobiana (Catão, 2007).

A Tabela 1 também apresenta os resultados da atividade antimicrobiana do extrato etanólico e fase acetato de etila de bom nome sobre linhagens ATCC de S.aureus, E. coli, e $P$. aeruginosa além de Salmonella sp. de origem ambiental e S.aureus de origem nosocomial. Observou-se comportamento semelhante entre as linhagens multirresistentes de S.aureus quando comparada com a cepa S.aureus ATCC 25923 usada como controle, tanto para o extrato como para a fase, ambos com valor de CIM de $400 \mathrm{mg} \mathrm{mL}^{-1}$.

De acordo com os resultados obtidos, podese sugerir que ambos os produtos apresentam atividade antimicrobiana semelhantes, tendo eficácia frente a bactéria Gram positiva Staphylococus aureus, mas não apresentam atividade antimicrobiana quando testados frente às bactérias Gram negativas E. coli ATCC 25922, P. aeruginosaATCC 27853 e Salmonella $\mathrm{sp.}$

É provável que esta diferença de atividade antimicrobiana esteja relacionada não só a atividade biológica dos produtos testados, mas também devido à presença de uma das estruturas da membrana externa das bactérias Gram negativas, que pode impedir a passagem de moléculas através desta membrana (França et al., 2009), além de particularidades relacionadas aos diferentes mecanismos de resistência das linhagens em estudo.

Nos últimos anos diversos estudos têm sido desenvolvidos visando a determinação da atividade antimicrobiana de várias espécies vegetais (Naqui et al., 1991; Nascimento et al., 2000; Pistelli et al., 2002; Rabanal et al., 2002; Antunes et al., 2006; Arruda et al., 2006; Kloucek, et al., 2006; França et al., 2009; Catão et al., 2010). Este estudo fornece os primeiros relatos de resultados que demonstram a eficácia do extrato etanólico e da fase acetato de etila de Maytenus rigida, sobre todas as linhagens de Staphylococus aureus testadas. Entretanto, são necessários outros estudos, inclusive, empregando outras metodologias, com o intuito de corroborar e assegurar os resultados aqui encontrados, que demonstram que $M$. rigida tem grande potencial para fornecer substâncias com atividade antibacteriana in vitro frente a micro-organismos Gram positivos.

\section{AGRADECIMENTO}

As Professoras Maria de Fátima Agra, Patrícia Maria de Freitas e Maricelma Ribeiro Morais pelo acesso e fornecimento do material de pesquisa.

\section{REFERÊNCIA}

AGRA, M.F.; FREITAS, P.F.; BARBOSA-FILHO, J.M. Synopsis of the plants known as medicinal and poisonous in Northeast of Brazil. Revista Brasileira de Farmacognosia, v.17, p.114-40, 2007.

ALMEIDA, C.F.C.B.R. et al. Life strategy and chemical composition as predictors of the selection of medicinal plants from the caatinga (Northeast Brazil). Journal of the Ethnopharmacology, v.62, p.127-42, 2005.

ANDRADE-LIMA, D. Plantas das Caatingas. Rio de Janeiro: A tribuna de Santos, 1989. 243p.

ANTUNES, R.M.P. et al. Atividade antimicrobiana "in vitro" e determinação da concentração inibitória mínina (CIM) de fitoconstituintes e produtos sintéticos sobre bactérias e fungos leveduriformes. Revista Brasileira de Farmacognosia, v.16, p.517-24, 2006.

ARRUDA, T.A. et al. Preliminary study of the antimicrobial activity of Mentha $x$ villosa Hudson essential oil, rotundifolone and its analogues. Revista Brasileira de Farmacognosia, v.16, p.307-11, 2006.

BAUER A.W. et al. Antibiotic susceptibility testing by a standartized single disk method. American Journal of Clinical Pathology, v.45, p.493-6, 1966.

BRUNI, R. et al. Antimutagenic, antioxidant and antimicrobial properties of Maytenus krukovii bark. Fitoterapia, v.77, p.538-45, 2006.

CALIXTO, J.B. Twenty-five years of research on medicinal plants in Latin America. A personal view. Journal of the Ethnopharmacology, v.100, p.131-4, 2005.

CARRICONDE, C. Bom nome, Maytenus rigida, Mart. De volta às raízes, v.19, p.1-2, 2004.

CATÃO, R.M.R. et al. Avaliação da atividade antimicrobiana de Riparinas sobre cepas de Staphylococcus aureus e Escherichia coli multirresistentes. Revista Brasileira de Análises Clínicas, v.37, n.4, p.247-9, 2005.

CATÃO, R.M.R. Atividade antimicrobiana e efeitos biológicos de riparinas sobre bactérias e fungos leveduriformes. 2007. 126p. Tese (Doutorado - Área de Concentração em Farmacologia) - Departamento de Farmácia, Universidade Federal da Paraíba, João Pessoa.

CATÃO, R.M.R. et al. Avaliação da atividade antimicrobiana e de feitos biológicos de riparinas sobre eliminação de resistência a drogas em amostras de Staphylococcus aureus. Revista Brasileira de Análises Clínicas, v.42, p.9-14, 2010. 
DELLE, M.F.; MARINI, B.G.B.; BERNAYS, E.A. Isolation of insect antifeedant alkaloids from Maytenus rigida (Celastraceae). Zeitschrift fuer Angewandte Entomologie, v.97, p.406-14, 1984.

DIAS, K.S. et al. Antinociceptive activity of Maytenus rigida stem bark. Fitoterapia, v.78, p.7-8, 2007.

ESTEVAM, C.S. Estudo fitoquímico biomonitorado da entrecasca de Maytenus rigida Mart. (Celastraceae). 2006. 189p. Tese (Doutorado - Área de concentração em Química) - Departamento de Química, Universidade Federal de Alagoas, Maceió.

FRANÇA, H.S. et al. Atividade antibacteriana de floroglucinóis e de extrato hexânico de Hypericum brasiliense Choysi. Química Nova, v.32, p.1103-6, 2009. GONZÁLEZ, A.G. et al. A revised structure for the triterpene rigidenol. Phytochemistry, v.21, p.470-1, 1982.

JORGE, R.M. et al. Evaluation of antinociceptive, antiinflammatory and antiulcerogenic activities of Maytenus ilicifolia. Journal of the Ethnopharmacology, v.94, p.93100, 2004.

KLOUCEK, P. et al. Antimicrobial activity of some medicinal barks used in Peruvian Amazon. Journal of the Ethnopharmacology, v.4, p.427-9, 2006.

MAY, J. et al. Time-kill studies of tea tree oils on clinical isolates. Journal of Antimicrobial Chemotherapy, v.45, n.5, p.639-43, 2000.

MACKENZIE, F.M.; MILNE, K.E.; GOULD, I.M. Calculation of composite recovery time: a new pharmacodynamic parameter. Journal of Antimicrobial Chemotherapy, v.50, p.281-4, 2002.

NAQUI, S.H.; KILIAN, M.S.Y.; VOHORA, S.B. Anti-bacterial, anti-fungal and antihelmintic investigations on Indian medicinal plants. Fitoterapia, v.62, n.3, p.221-8, 1991. NASCIMENTO, G.G.F.; LOCATELLI, J.; FREITAS, P.C.D. Antibacterial activity of plant extracts and phytochemicals on antibiotic-resistant bacteria. Brazilian Journal of Microbiology, v.31, n.4, p.247-56, 2000.

NATIONAL COMMITTEE FOR CLINICAL LABORATORY STANDART - NCCLS, Padronização dos Testes de sensibilidade a Antimicrobianos por Disco-difusão; Norma Aprovada. 8.ed. M2-18. Wayne: NCCLS, v.23. n.1. NOLDIN, V.F.; ISAIAS, D.B.; CECHINEL FILHO, V. Gênero Calophyllum: importância clínica e farmacológica.
Química Nova, v.29, p.549-54, 2006.

OLIVEIRA, A.F.M. et al. Friedelan-3â-ol, an abundant foliar triterpene of Maytenus rigida Mart. (Celastraceae). Bollettino Chimico Farmaceutico, v.138, p.186-9, 1999. OLIVEIRA, A.F.M.; SALATINO, A. Major constituents of the epicuticular waxes of species from the caatinga and Cerrado. Zeitschrift für Naturforschung, v.55, p.688-92, 2000.

OMENA, M.L.R.A. Ensaio etnofarmacológico de espécies vegetais com ação no sistema nervoso central, originárias do bioma caatinga. Saúde \& Ambiente em Revista, v.2, p.92-107, 2007.

PISTELLI, L. et al. Chemical and antibacterial evaluation of Hypericum triquetrifolium Turra. Phytotherapy Research, v.19, p.787-91, 2002.

RABANAL, R.M. et al. Antimicrobial studies on three species of Hypericum from the Canary Islands. Journal of the Ethnopharmacology, v.81, p.287-92, 2002.

SANTOS, V.L. et al. Pharmacological studies of ethanolic extracts of Maytenus rigida Mart (Celastraceae) in animal models. Revista Brasileira de Farmacognosia, v.17, p.336-42, 2007.

SANTOS, V.L. Avaliação da atividade antiulcerogênica, antidiarréica e antiespasmódica do extrato etanólico bruto e fase acetato de etila obtidos da entrecasca do caule de Maytenus rigida Mart. (Celastraceae) em modelos animais. 2008. 118p. Tese (Doutorado - Área de Concentração em Farmacologia) - Departamento de Farmácia, Universidade Federal da Paraíba, João Pessoa.

SILVEIRA, L.M.S. et al. Metodologias de atividade antimicrobiana aplicadas a extratos de plantas: comparação entre duas técnicas de ágar difusão. Revista Brasileira de Farmácia, v.90, n.2, p.124-8, 2009. SPIVEY, A.C.; WESTON, M.; WOODHEAD, S. Celastraceae sesquiterpenoids: biological activity and synthesis. Chemical Society Reviews, v.31, p.43-59, 2002.

VON EIFF, C.; PETERS, G.; HEILMANN, C. Pathogenesis of infections due to coagulase-negative staphylococci. Lancet Infect Diseases, v.2, p.677-85, 2002.

WONG-LEUNG, Y.L. Antimicrobial activities of some Hong-Kong plants used in chinese medicine. Fitoterapia, v.69, p.11-6, 1988. 